\title{
Inhibitory effect of the Kampo medicinal formula Yokukansan on acute stress-induced defecation
} in rats

\author{
Yasuaki Kanada \\ Ayami Katayama \\ Hideshi Ikemoto \\ Kana Takahashi \\ Mana Tsukada \\ Akio Nakamura \\ Shogo Ishino \\ Tadashi Hisamitsu \\ Masataka Sunagawa
}

Department of Physiology, School of Medicine, Showa University,

Shinagawa-ku, Tokyo, Japan
Correspondence: Masataka Sunagawa Department of Physiology, School of Medicine, Showa University, I-5-8 Hatanodai, Shinagawa-ku, Tokyo 142-8555, Japan

Tel $+8 \mid 337848$ II 0

Fax +81337845368

Email suna@med.showa-u.ac.jp
This article was published in the following Dove Press journal: Neuropsychiatric Disease and Treatment

Objectives: Irritable bowel syndrome (IBS) is a functional gastrointestinal disorder with symptoms of abnormal defecation and abdominal discomfort. Psychological factors are well known to be involved in onset and exacerbation of IBS. A few studies have reported effectiveness of traditional herbal (Kampo) medicines in IBS treatment. Yokukansan (YKS) has been shown to have anti-stress and anxiolytic effects. We investigated the effect of YKS on defecation induced by stress and involvement of oxytocin (OT), a peptide hormone produced by the hypothalamus, in order to elucidate the mechanism of YKS action.

Methods and results: Male Wistar rats were divided into four groups; control, YKS $(300 \mathrm{mg} / \mathrm{kg}$ PO)-treated non-stress (YKS), acute stress (Stress), and YKS (300 mg/kg PO)-treated acute stress (Stress+YKS) groups. Rats in the Stress and Stress+YKS groups were exposed to a 15-min psychological stress procedure involving novel environmental stress. Levels of plasma OT in the YKS group were significantly higher compared with those in the Control group $(P<0.05)$, and OT levels in the Stress+YKS group were remarkably higher than those in the other groups $(P<0.01)$. Next, rats were divided into four groups; Stress, Stress+YKS, Atosiban (OT receptor antagonist; $1 \mathrm{mg} / \mathrm{kg}$ IP)-treated Stress+YKS (Stress+YKS+B), and OT (0.04 mg/kg IP)-treated acute stress (Stress+OT) groups. Rats were exposed to acute stress as in the previous experiment, and defecation during the stress load was measured. Administration of YKS or OT significantly inhibited defecation; however, administration of Atosiban partially abolished the inhibitory effect of YKS. Finally, direct action of YKS on motility of isolated colon was assessed. YKS $(1 \mathrm{mg} / \mathrm{mL}, 5 \mathrm{mg} / \mathrm{mL})$ did not inhibit spontaneous contraction.

Conclusion: These results suggested that YKS influences stress-induced defecation and that increased OT secretion may be a mechanism underlying this phenomenon.

Keywords: Yokukansan, oxytocin, irritable bowel syndrome, acute stress, corticosterone, Kampo medicine

\section{Introduction}

Irritable Bowel Syndrome (IBS) is a disorder with an increasing number of cases in recent years. The prevalence rate in Japan is $10 \%-15 \%$ and the number of patients is estimated to be 12 million. ${ }^{1,2}$ IBS is a functional gastrointestinal disorder characterized by the presence of recurrent abdominal pain with abnormalities in stool frequency and form. No physical or biochemical abnormalities underlying the symptoms have been found. IBS is thought to be caused by diverse etiologies, and psychological factors are often related to its onset and deterioration. 3 .4 Psychological abnormalities affect intestinal motility through the central nervous system, for example, colon movement is accelerated by negative emotions such as anxiety, fear, and stress. ${ }^{5,6}$ Intestinal function 
and central nervous system are known to be closely related, referred to as "brain-gut interaction". This interaction is suggested to be influenced by the hypothalamic-pituitaryadrenal (HPA) axis, the autonomous nervous system, and the immune system. ${ }^{6,7}$

IBS patients are categorized into subgroups including IBS with diarrhea (IBS-D), IBS with constipation (IBS-C), IBS with mixed diarrhea and constipation (IBS-M), and unclassified IBS. Drug therapy used for IBS-D primarily includes serotonin-3 (5-HT) $)_{3}$ receptor antagonists, anticholinergic drugs, antidiarrheal drugs, and selective serotonin reuptake inhibitors. ${ }^{2,8}$ Recently, effective examples of traditional herbal medicines (Kampo medicines) such as Keishikashakuyakuto and Rikkunshito have been reported. ${ }^{9}$

Yokukansan (YKS) is a Kampo medicinal formula composed of seven medicinal herbs (Table 1). ${ }^{10}$ YKS has been used for the treatment of emotional irritability, neurosis, insomnia, and night terrors and temper tantrums in children. ${ }^{10}$ In clinical practice, YKS has been used in behavioral and psychological symptoms of dementia, ${ }^{11,12}$ pain disorders, ${ }^{13}$ and anxiety disorders. ${ }^{14,15}$ The anti-stress ${ }^{16,17}$ and anxiolytic effects $^{18,19}$ of YKS have been reported in basic research studies. In a clinical report, Sempuku ${ }^{20}$ reported a case wherein Yokukansankachinpihange, which includes the nine ingredients found in YKS, was effective in treating IBS. Therefore, we expected that YKS may also be effective in treating IBS patients affected psychologically.

It has been recently reported that oxytocin (OT) is involved in the control of intestinal motility. ${ }^{21-23}$ OT is a neuropeptide produced in the hypothalamus, acting centrally via nerve axons and systemically via blood circulation. Studies in animals have demonstrated that intracerebroventricular administration of OT inhibited production and biological activity of corticotropin releasing factor (CRF) in the paraventricular nucleus of the hypothalamus following acute or chronic stress, and controlled gastrointestinal motility induced by stress exposure. ${ }^{24-26}$ Moreover, OT and

Table I Component galenicals of YKS

\begin{tabular}{lll}
\hline Plant name & Weight & Major active components \\
\hline Uncariae cum Uncis ramulus & $3.0 \mathrm{~g}$ & $\begin{array}{l}\text { Rhynchophylline, } \\
\text { Geissoschizine methyl ether }\end{array}$ \\
Cnidii rhizoma & $3.0 \mathrm{~g}$ & Ligustilide, Senkyunolide \\
Bupleuri radix & $2.0 \mathrm{~g}$ & Saikosaponin a, c, d, e, f \\
Atratylodis Lanceae rhizoma & $4.0 \mathrm{~g}$ & Atractylodin, $\beta$-eudesmol \\
Poria & $4.0 \mathrm{~g}$ & Eburicoic acid, Pachymic acid \\
Angelicae radix & $3.0 \mathrm{~g}$ & Ligustilide, n-butylidenphthalide \\
Glycyrrhizae radix & $\mathrm{I.5 \textrm {g }}$ & Glycyrrhizin, Glycyrrhizic acid \\
\hline
\end{tabular}

Note: Weights show the amounts mixed.

Abbreviation: YKS, Yokukansan.
OT-receptor mRNA are expressed throughout the gastrointestinal tract, ${ }^{27}$ and OT has been shown to inhibit colon ${ }^{28,29}$ and stomach ${ }^{30}$ motility in vitro. It has also been reported that intraperitoneal administration (IP) of OT inhibited stress-induced colonic contraction in rats. ${ }^{25}$ In the current study, the effects of YKS on increased intestinal motility induced by stress, and involvement of OT in YKS action were evaluated.

\section{Materials and methods}

\section{Animals}

Male Wistar rats (7-8 weeks old), purchased from Nippon Bio-Supp. Center (Tokyo, Japan), were used. During the experimental period, the animals were housed in standard plastic cages in our animal facilities at $25^{\circ} \mathrm{C} \pm 2{ }^{\circ} \mathrm{C}$ with $55 \% \pm 5 \%$ humidity under a light/dark cycle of $12 \mathrm{~h} / 12 \mathrm{~h}$. Food (CLEA Japan, CE-2, Tokyo, Japan) and water were provided ad libitum. Experiments were performed as per the guidelines of the Committee of Animal Care and Welfare of Showa University. All experimental procedures were approved by the Committee of Animal Care and Welfare of Showa University (certificate number: 07061).

\section{Drugs}

Dry powdered extracts of YKS (Lot No 2110054010) used in the present study were supplied by Tsumura \& Co. (Tokyo, Japan). The seven herbs comprising YKS (Table 1) were mixed and extracted with purified water at $95.1^{\circ} \mathrm{C}$ for $1 \mathrm{~h}$, a soluble extract was separated from insoluble waste and concentrated by removing water under reduced pressure. YKS was dissolved in distilled water and orally administered. OT (Peptide Institute, Osaka, Japan) and Atosiban, an OT-receptor antagonist (Sigma-Aldrich, St Louis, MO, USA), were dissolved in saline and intraperitoneally administered.

\section{Influence of YKS and acute stress on OT secretion}

To evaluate effects of YKS and acute stress on OT secretion, 28 rats were randomly divided into four groups (seven per group) as follows: (1) Control group; (2) YKS-treated non-stress (YKS) group; (3) acute stress (Stress) group, and (4) YKS-treated acute stress (Stress+YKS) group. YKS (300 mg/kg/day) was administered daily for 3 days to the YKS and Stress+YKS groups, and water was administered orally to the Control and Stress groups. In preliminary experiments, single administration of YKS did not show inhibitory 
effects on increased defecation (data not shown), and YKS was therefore pre-administered for 3 days. YKS dose was chosen based on the results of published studies. ${ }^{17,31}$ It has been reported that OT is involved in stress responses. ${ }^{32,33}$ In our study, we investigated the influence of acute psychological stress on OT secretion. On day 4, $1 \mathrm{~h}$ after administration of YKS or water, rats in the Stress and the Stress+YKS groups were exposed to $15 \mathrm{~min}$ of an acute stress procedure, involving novel environmental stress. ${ }^{34,35}$ Each rat was transferred from group-housed cages and placed in an opaque box $\left(60 \times 60 \times 60 \mathrm{~cm}^{3}\right)$ individually for $15 \mathrm{~min}$. Next, all rats were anesthetized with intraperitoneal pentobarbital sodium (50 mg/kg; Kyoritsu Seiyaku, Somnopentyl, Tokyo, Japan), and blood samples were obtained from the inferior vena cava. To avoid influences of fluctuation in routine, all blood sampling was performed between 13:00 $\mathrm{h}$ and 15:00 $\mathrm{h}$. Blood samples were centrifuged at $4^{\circ} \mathrm{C}$ and $3,000 \mathrm{rpm}$ for $10 \mathrm{~min}$, and supernatants collected. The plasma was stored at $-80^{\circ} \mathrm{C}$ until measurements. Acetonitrile was used for the precipitation of plasma proteins. The thawed plasma was mixed with acetonitrile (Wako Pure Chemical Industries, Osaka, Japan) and centrifuged. Subsequently, the supernatant was evaporated and reconstituted with the assay buffer. Plasma OT level was measured using an enzyme-linked immunosorbent assay (ELISA) kit (Enzo Life Sciences, Farmingdale, NY, USA), according to the manufacturer's instructions.

\section{Intraperitoneal administration of OT}

To determine the dose of OT to be used in subsequent experiments, OT was intraperitoneally administered to rats and plasma OT concentrations were measured. Doses of OT were $0.02 \mathrm{mg} / \mathrm{kg}$ (ОT0.02; $=6), 0.04 \mathrm{mg} / \mathrm{kg}$ (ОT0.04; $=6$ ), and $0.20 \mathrm{mg} / \mathrm{kg}($ OT0.20; $\mathrm{n}=6)$. These doses were determined by referring to a previous study..$^{24}$ It was reported that intraperitoneal administration of OT ( $500 \mathrm{pmol}$ per rat) inhibited water-avoidance stress-induced colonic contraction in rats. Control rats $(n=6)$ were intraperitoneally administered with saline. One hour after administration, plasma OT concentrations were measured using the method described above.

\section{Acute stress-induced defecation}

It is known that defecation in rats is increased by an acute stress load, and this model is used for studies on IBS-D. ${ }^{36}$ Thirty-six rats were randomly divided into four groups (nine per group) as follows: (1) acute stress (Stress); (2) YKStreated acute stress (Stress+YKS); (3) Atosiban-treated Stress+YKS (Stress+YKS+B); and (4) OT-treated acute stress (Stress+OT). YKS $(300 \mathrm{mg} / \mathrm{kg} /$ day $)$ or water was orally administered daily for 3 days. On day 4, rats in the Stress+OT group were administered OT $(0.04 \mathrm{mg} / \mathrm{kg}$, IP $)$ $1 \mathrm{~h}$ before the stress load, and those in the Stress+YKS+B group were administered Atosiban (1 mg/kg, IP) $10 \mathrm{~min}$ before YKS administration. In the Stress and Stress+YKS groups, saline was administered instead of Atosiban or OT (Table 2). One hour after administration of YKS or water, rats were exposed to acute stress, and defecation during the stress load was measured using a balance. Atosiban dose was determined based on a previous study. ${ }^{37}$

\section{Influence of YKS and acute stress on corticosterone secretion}

Levels of plasma corticosterone, which reflects activation of the HPA axis, were measured. ${ }^{38}$ Twenty-four rats were randomly divided into four groups (six per group) as follows: (1) Control; (2) acute stress (Stress); (3) YKS-treated acute stress (Stress+YKS); and (4) OT-treated acute stress (Stress+OT). Drug administration, stress load, and blood sampling were conducted as described above. Corticosterone levels were measured using an ELISA kit (Enzo Life Sciences).

\section{Recording of colon contraction}

We investigated whether the inhibitory effect of YKS on increased defecation was mediated via direct action on the bowel. Segments of the distal colon were isolated from five intact rats and were longitudinally cut into $15 \times 5 \mathrm{~mm}^{2}$ strips, and then transferred to a $20-\mathrm{mL}$ organ bath. The organ baths contained aerated $\left(5 \% \mathrm{CO}_{2}, 95 \% \mathrm{O}_{2}\right)$ Kreb's solution (composed of $\mathrm{NaCl} 6.9 \mathrm{~g} / \mathrm{L}, \mathrm{KCl} 0.36 \mathrm{~g} / \mathrm{L}, \mathrm{KH}_{2} \mathrm{PO}_{4} 0.16 \mathrm{~g} / \mathrm{L}$,

Table 2 Drugs administered in the study of stress-induced defecation

\begin{tabular}{lll}
\hline Groups & Day I-3 & Day 4 \\
\hline Stress $(\mathrm{n}=9)$ & Water $(\mathrm{PO})$ & Water $(\mathrm{PO})+$ saline $(\mathrm{IP})$ \\
Stress+YKS $(\mathrm{n}=9)$ & YKS $(300 \mathrm{mg} / \mathrm{kg} /$ day, $\mathrm{PO})$ & YKS $(300 \mathrm{mg} / \mathrm{kg} / \mathrm{day}, \mathrm{PO})+$ saline $(\mathrm{IP})$ \\
Stress+YKS+B $(\mathrm{n}=9)$ & YKS $(300 \mathrm{mg} / \mathrm{kg} /$ day, $\mathrm{PO})$ & $\mathrm{YKS}(300 \mathrm{mg} / \mathrm{kg} / \mathrm{day}, \mathrm{PO})+\mathrm{Atosiban}(\mathrm{I} \mathrm{mg} / \mathrm{kg}, \mathrm{IP})$ \\
Stress+OT $(\mathrm{n}=9)$ & Water $(\mathrm{PO})$ & Water $(\mathrm{PO})+$ OT $(0.04 \mathrm{mg} / \mathrm{kg}, \mathrm{IP})$ \\
\hline
\end{tabular}

Note: Drugs administered in the study of stress-induced defecation.

Abbreviations: B, blocker of oxytocin receptor; IP, intraperitoneal administration; OT, oxytocin; PO, per os; YKS, Yokukansan. 
$\mathrm{MgSO}_{4} 0.14 \mathrm{~g} / \mathrm{L}, \mathrm{CaCl}_{2} 0.28 \mathrm{~g} / \mathrm{L}, \mathrm{NaHCO}_{3} 2.1 \mathrm{~g} / \mathrm{L}$, and glucose $1.8 \mathrm{~g} / \mathrm{L}$ ) maintained at $37^{\circ} \mathrm{C}$. The colon segments were suspended in Kreb's solution with an initial tension of $2.0 \mathrm{~g}$ for recording. Then, YKS dissolved in Kreb's solution was perfused into the bath at $5 \mathrm{~mL} / \mathrm{min}$ after stable colonic contractions were established. The YKS concentrations used were $1 \mathrm{mg} / \mathrm{mL}$ and $5 \mathrm{mg} / \mathrm{mL}$ based on previous reports. ${ }^{39}$ Colon contractions were recorded with a force displacement transducer (FD Pickup TB-611T; Nihon Koden, Tokyo, Japan) and a PowerLab data acquisition system (ADInstruments, Dunedin, New Zealand).

\section{Statistical analysis}

All experimental data are presented as mean \pm standard error of mean (SEM). Statistical significance of differences between groups was evaluated using paired $t$-test for comparisons between two groups, and one-way analysis of variance (ANOVA) for comparisons among $>2$ groups. Post hoc comparisons between the four groups were performed using the Tukey's post hoc test. All $P$-values $<0.05$ were considered to be statistically significant.

\section{Results}

\section{Influence of YKS and acute stress on OT secretion}

The influence of YKS and acute psychological stress on OT secretion was investigated. Administration of $300 \mathrm{mg} / \mathrm{kg} /$ day YKS significantly increased plasma OT levels compared with those in the control group (Control, $14.47 \pm 0.96 \mathrm{pg} / \mathrm{mL}$; YKS, $19.43 \pm 0.86 \mathrm{pg} / \mathrm{mL} ; P<0.05)$. No significant difference was observed between the Control and Stress groups (Stress, $15.74 \pm 0.83 \mathrm{pg} / \mathrm{mL}$ ); however, OT level in the Stress+YKS group was markedly increased compared with the other groups (Stress+YKS, $27.47 \pm 1.47 \mathrm{pg} / \mathrm{mL}$; $P<0.01$ ) (Figure 1).

\section{Intraperitoneal administration of OT}

Plasma OT concentrations were measured $1 \mathrm{~h}$ after intraperitoneal administration of OT $(0,0.02,0.04$, and $0.20 \mathrm{mg} / \mathrm{kg})$. The results are shown in Table 3. The plasma OT level in the OT (0.04) group was almost identical to that in the Stress+YKS group $(27.47 \pm 1.47 \mathrm{pg} / \mathrm{mL}$; Figure 1); therefore, OT dose in subsequent experiments was set to $0.04 \mathrm{mg} / \mathrm{kg}$.

\section{Acute stress-induced defecation}

Defecation during the 15-min stress load was measured by weighing. Acute stress load-induced defecation $(1.31 \pm 0.23 \mathrm{~g})$, and defecation in the absence of stress were significantly suppressed by pre-administrations of YKS $(0.14 \pm 0.09 \mathrm{~g})$

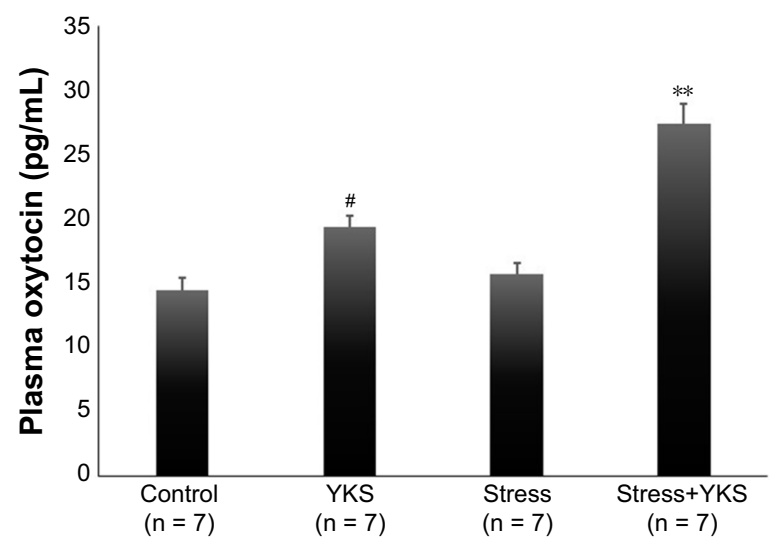

Figure I Plasma oxytocin levels $(\mathrm{pg} / \mathrm{mL})$ following administration of YKS and acute stress load.

Notes: Data are presented as mean \pm SEM. Statistical analysis: one-way ANOVA followed by Tukey's post hoc test, ${ }^{\#} P<0.05$ (vs Control group), ${ }^{* * P}<0.0$ I (vs other groups).

Abbreviations: ANOVA, analysis of variance; SEM, standard error of mean; YKS, Yokukansan.

and OT $(0.18 \pm 0.11 \mathrm{~g})(P<0.01)$. However, administration of Atosiban decreased the effect of YKS $(0.71 \pm 0.23 \mathrm{~g})$ (Figure 2).

\section{Influence of YKS and acute stress on corticosterone secretion}

Influence of YKS and acute psychological stress on plasma corticosterone levels were also investigated. Plasma corticosterone level was significantly increased in the Stress and Stress-OT groups compared with that in the Control group (Control, $71.08 \pm 17.43 \mathrm{ng} / \mathrm{mL}$; Stress, $192.61 \pm 14.72 \mathrm{ng} / \mathrm{mL}$; Stress+OT, $210.33 \pm 32.40 \mathrm{ng} / \mathrm{mL} ; P<0.01$ ); however, there was no significant difference between the Control and Stress+YKS groups $(128.51 \pm 17.06 \mathrm{ng} / \mathrm{mL})(P=0.266)$ (Figure 3).

\section{Influence of YKS on isolated colon contraction}

Spontaneous muscle contractions vary in their tension and frequency among muscle preparations. Thus, baseline recordings were obtained as controls during 10 min prior to administration of YKS and compared with a 10-min period

Table 3 Plasma OT concentrations

\begin{tabular}{lllll}
\hline $\mathbf{p g} / \mathrm{mL})$ & $\begin{array}{l}\text { Control } \\
(\mathbf{n}=\mathbf{6})\end{array}$ & $\begin{array}{l}\text { OT (0.02) } \\
(\mathbf{n}=\mathbf{6})\end{array}$ & $\begin{array}{l}\text { OT (0.04) } \\
(\mathbf{n}=\mathbf{6})\end{array}$ & $\begin{array}{l}\text { OT (0.20) } \\
(\mathbf{n}=\mathbf{6})\end{array}$ \\
\hline Average & 15.36 & 15.13 & 27.70 & 270.45 \\
SEM & 1.58 & 3.41 & 9.12 & 10.25 \\
\hline
\end{tabular}

Note: Plasma OT concentrations $(\mathrm{pg} / \mathrm{mL})$ following the intraperitoneal administration of OT $(0,0.02,0.04$ and $0.20 \mathrm{mg} / \mathrm{mL})$.

Abbreviations: OT, oxytocin; SEM, standard error of mean. 


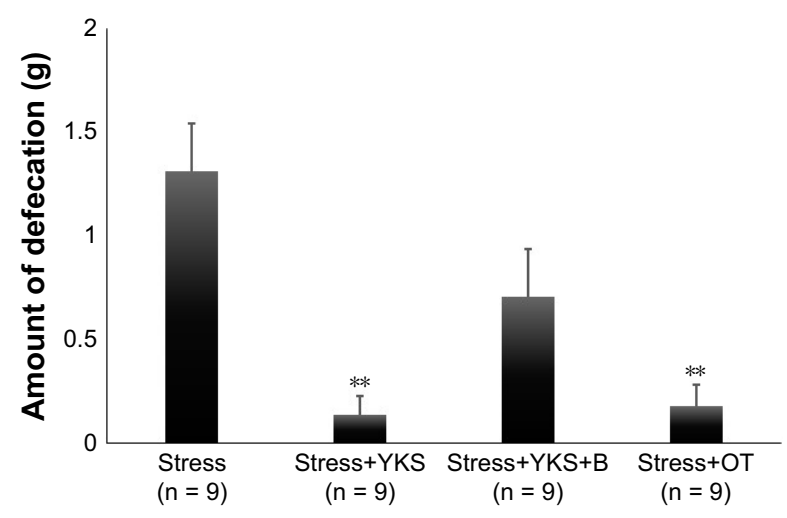

Figure 2 Amount of defecation (g) following the acute stress load. Notes: Data are presented as mean \pm SEM. Statistical analysis: one-way ANOVA followed by Tukey's post hoc test, **P $<0.0$ I (vs Stress group).

Abbreviations: ANOVA, analysis of variance; B, blocker of oxytocin receptor; OT, oxytocin; SEM, standard error of mean; YKS, Yokukansan.

after YKS administration to assess response. Representative contraction waves are shown in Figure 4A (YKS $1 \mathrm{mg} / \mathrm{mL}$ ) and 4B (YKS $5 \mathrm{mg} / \mathrm{mL}$ ). Contractile amplitude (g) was obtained by integrating area under the contractile wave above baseline. The amplitudes before and after administration of $1 \mathrm{mg} / \mathrm{kg}$ YKS did not show a significant difference (before, $49.15 \pm 3.23 \mathrm{~g}$; after, $54.63 \pm 6.18 \mathrm{~g}$ ) (Figure 4C). The value after administration of $5 \mathrm{mg} / \mathrm{kg}$ YKS was higher compared with that before administration (before, $50.85 \pm 5.04 \mathrm{~g}$; after, $76.57 \pm 12.32 \mathrm{~g})(P=0.052)$ (Figure 4D). Overall, YKS did not appear to directly inhibit colonic motility.

\section{Discussion}

This study addressed the use of Kampo medicines as potential treatment for patients with IBS-D, by evaluating effectiveness

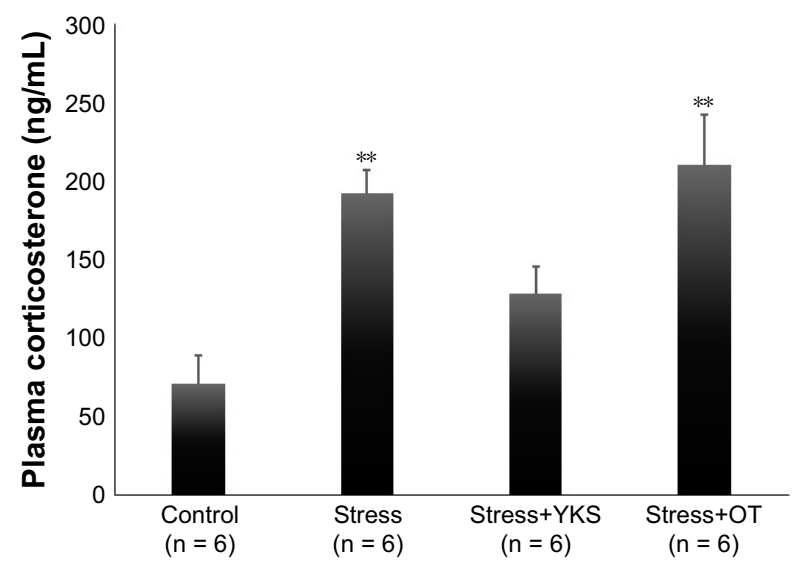

Figure 3 Plasma corticosterone levels $(\mathrm{ng} / \mathrm{mL})$ following administration of YKS and the acute stress procedure.

Notes: Data are presented as mean \pm SEM. Statistical analysis: one-way ANOVA followed by Tukey's post hoc test, **P $<0.0$ I (vs Control group).

Abbreviations: ANOVA, analysis of variance; OT, oxytocin; SEM, standard error of mean; YKS, Yokukansan. and mechanism of YKS in a rat model with increased defecation induced by stress. ${ }^{25}$

It has been reported that YKS shows $5-\mathrm{HT}_{1 \mathrm{~A}}$ receptor agonist action, ${ }^{18} 5-\mathrm{HT}_{2 \mathrm{~A}}$ receptor downregulation, ${ }^{40}$ inhibition of glutamate secretion, ${ }^{41}$ enhancement of glutamate clearance from extracellular fluid by astrocytes, ${ }^{42}$ and $N$-methylD-aspartate (NMDA) receptor antagonism. ${ }^{43}$ However, no reports concerning its action on OT secretion are present. Therefore, in the present study, we examined the influence of YKS on OT secretion and whether peripheral OT is involved in the control of defecation induced by acute stress.

First, influences of pre-administration of YKS and acute psychological stress on OT secretion in rats were investigated. Administration of YKS promoted peripheral secretion of OT, which was further increased under the 15-min novel environmental stress conditions, although OT level did not change under the stress alone (Figure 1). Previous studies showed that some acute stressors, ${ }^{44,45}$ such as immobilization, ether exposure, and forced swimming, increase the plasma OT levels but not after novel stress load. ${ }^{44,46}$

The level was unchanged in the present study as well. The trends in the secretion of OT seem to be different depending on the types of stressors. These results suggested that administration of YKS might enhance sensitivity of OT neurons to stress. Zheng et $\mathrm{al}^{24}$ reported that adaptation to stress may involve upregulation of OT expression in the hypothalamus, which in turn attenuates CRF expression. YKS is thus expected to enhance resistance against stress.

Next, the inhibitory effect of YKS on defecation induced by stress was examined, and the amount of feces in the Stress+YKS group significantly decreased compared with that in the Stress group (Figure 2). Mizoguchi et $\mathrm{al}^{47}$ also reported that pre-administration of YKS in aged rats for 3 months inhibited the anxiety-related defecation under a novel environment and that the increases of serotonin and dopamine in the prefrontal cortex were also involved. Therefore, we investigated whether this action is a result of OT secretion. Atosiban, an OT receptor antagonist, was intraperitoneally administered before stress load. The result showed that the inhibitory effect of YKS was partially obstructed by Atosiban. Moreover, OT was intraperitoneally injected to result in a plasma OT level similar to that due to YKS administration (Figure 1, Table 2), and defecation was significantly decreased similar to that caused by YKS. Intraperitoneal injection of OT and Atosiban is not expected to result in brain entry due to the blood-brain barrier. ${ }^{48,49}$ Plasma corticosterone concentration, which reflects activation of the HPA axis, was also measured in this study. The level 
A

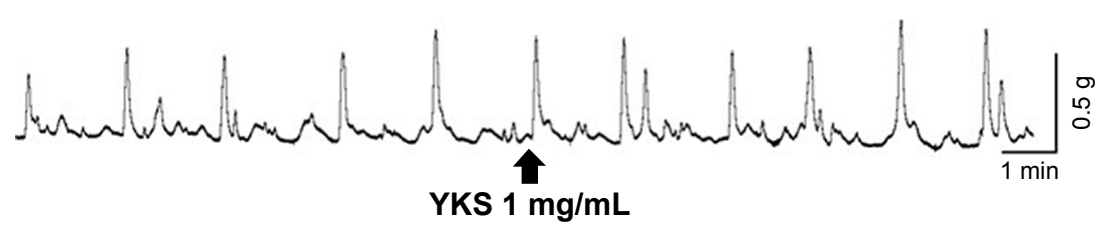

B

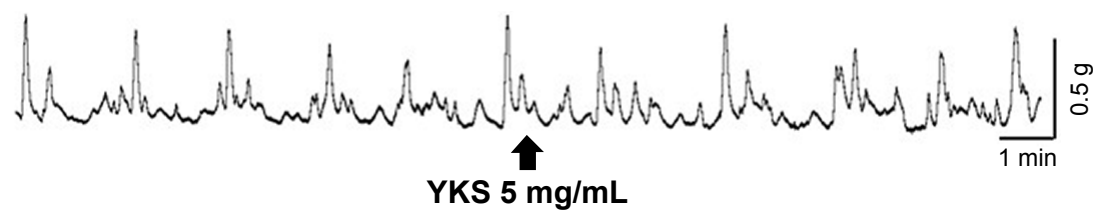

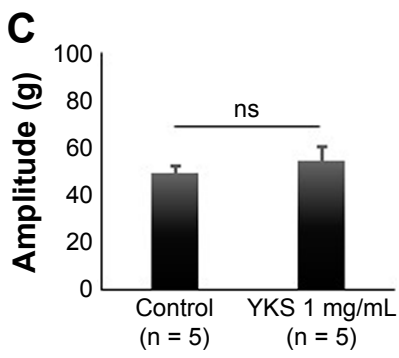

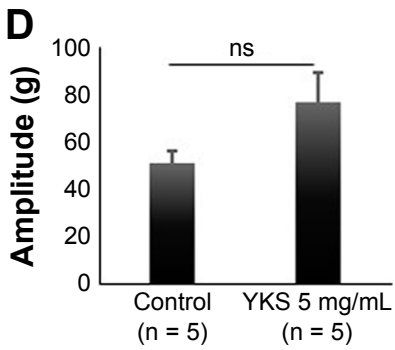

Figure 4 Effect of YKS on isolated colonic motility. Representative contraction wave acquired when administering YKS (I mg/mL) (A) and (5 mg/mL) (B). Contractile amplitudes (g) obtained by integrating area under the contractile wave above baseline $(\mathrm{I} \mathrm{mg} / \mathrm{mL})(\mathbf{C})$ and $(5 \mathrm{mg} / \mathrm{mL})(\mathbf{D})$.

Notes: Data are presented as mean \pm SEM. Statistical analysis: paired $t$-test.

Abbreviations: ns, not significant; SEM, standard error of mean; YKS, Yokukansan.

was significantly increased by the stress load; however, this significant increase was prevented by pre-administration of YKS (ns, comparing Stress+YKS and Control groups), but not OT. Central administration of OT inhibits the release of CRF, adrenocorticotropic hormone (ACTH), and corticosterone, ${ }^{24,25}$ also suggesting that OT was not delivered into the brain. Finally, the lack of a direct inhibitory effect of YKS on colonic motility was confirmed with studies on isolated colons (Figure 4). As described above, OT has a regulatory effect on bowel movement, acting on the OT receptor in the gastrointestinal tract. ${ }^{25,27-30}$ Based on the above results, YKS may control stress-induced defecation at least partially via peripheral OT secretion.

Paraventricular nuclei in the hypothalamus also deliver OT to several forebrain nuclei. YKS administration has a high probability of increasing OT secretion in the brain because the peripheral OT level increased. Intraventricular administration of OT has been shown to inhibit accelerated colonic motility induced by acute stress,${ }^{25}$ highlighting the need for more detailed studies to clarify the central mechanism of YKS.

Almost all OT neurons express both 5- $\mathrm{HT}_{1 \mathrm{~A}}$ and 5- $\mathrm{HT}_{2 \mathrm{~A}}$ receptors, ${ }^{50}$ and administration of $5-\mathrm{HT}_{1 \mathrm{~A}}$ receptor agonists increases secretion of OT. However, administration of a $5-\mathrm{HT}_{2 \mathrm{~A}}$ receptor agonist was shown to induce functional desensitization of 5-HT ${ }_{1 \mathrm{~A}}$ receptors, and pre-administration of a $5-\mathrm{HT}_{2 \mathrm{~A}}$ receptor antagonist prevented desensitization of 5-HT ${ }_{1 \mathrm{~A}}$ receptors. ${ }^{51}$ As mentioned above, YKS has been shown to have $5-\mathrm{HT}_{1 \mathrm{~A}}$ receptor agonist action ${ }^{18}$ and a $5-\mathrm{HT}_{2 \mathrm{~A}}$ receptor downregulation effect. ${ }^{40}$ In this study, YKS was pre-administered for 3 days before the stress load because single administration was not effective in preliminary experiments. Antagonist action on $5-\mathrm{HT}_{2 \mathrm{~A}}$ receptors for 3 days might enhance sensitivity of 5-HT ${ }_{1 \mathrm{~A}}$ receptors in OT neurons. In the neuropharmacological studies of YKS, geissoschizine methyl ether, an alkaloid synthesized by Uncariae cum Uncis ramulus, has been identified as an active compound and to have a partial 5- $\mathrm{HT}_{1 \mathrm{~A}}$ receptor agonistic action ${ }^{52}$ and $5-\mathrm{HT}_{2 \mathrm{~A}}$ receptor antagonistic action. ${ }^{53}$ Accordingly, the actions of Uncariae cum Uncis ramulus via the $5-\mathrm{HT}_{1 \mathrm{~A}}$ and 5- $\mathrm{HT}_{2 \mathrm{~A}}$ receptors may represent one of the mechanisms via which YKS affects OT neurons. Therefore, future studies are required to identify crude medicinals that regulate OT secretion as well as to identify their mechanisms. This is the first report to show that YKS increases plasma OT level and the possibility of using YKS to treat increased defecation induced by stress, similar to symptoms of abnormal defecation in IBS-D. OT is also reported to downregulate mesenteric afferent sensitivity through the nNOS-NO-KATP pathway, ${ }^{54}$ and therefore action of YKS via OT is also expected to play an analgesic role in modulating the decline of the pain threshold in IBS.

\section{Conclusion}

Our findings suggest that administration of YKS enhances sensitivity of OT neuron to stress, elevates secretion of OT, and controls stress-induced defecation. YKS is expected to be useful in treating abnormal defecation induced by stress. 


\section{Acknowledgments}

The authors are grateful to Tsumura \& Co. for generously providing YKS and to Prof Guo Shi-yu for generously providing instructions for recording colonic motility.

\section{Author contributions}

All authors made substantial contributions to conception and design, acquisition of data, or analysis and interpretation of data; took part in drafting the article or revising it critically for important intellectual content; gave final approval of the version to be published; and agree to be accountable for all aspects of the work.

\section{Disclosure}

The authors report no conflicts of interest in this work.

\section{References}

1. Miwa H. Prevalence of irritable bowel syndrome in Japan: Internet survey using Rome III criteria. Patient Prefer Adherence. 2008;2: 143-147.

2. The Japanese Society of Gastroenterology. Evidence-based clinical practice guidelines for irritable bowel syndrome. 1st ed. Tokyo, Nankodo; 2014.

3. Thompson WG, Longstreth GF, Drossman DA, Heaton KW, Irvine EJ, Müller-Lissner SA. Functional bowel disorders and functional abdominal pain. Gut. 1999;45(2):1143-1147.

4. Drossman DA, Chang L, Chey WD, Kellow J, Tack J, Whitehead WE, eds. Rome IV functional gastrointestinal disorders - disorders of gutbrain interaction. Vol. 1. 4th ed. North Carolina: Raleigh; 2016.

5. Rao SS, Hatfield RA, Suls JM, Chamberlain MJ. Psychological and physical stress induce differential effects on human colonic motility. Am J Gastroenterol. 1998;93(6):985-990.

6. Fukudo S, Saito K, Sagami Y, Kanazawa M. Can modulating corticotropin releasing hormone receptors alter visceral sensitivity? Gut. 2006;55(2):146-148.

7. Saito K, Kasai T, Nagura Y, Ito H, Kanazawa M, Fukudo S. Corticotropinreleasing hormone receptor 1 antagonist blocks brain-gut activation induced by colonic distention in rats. Gastroenterology. 2005; 129(5):1533-1543.

8. Fukudo S, Kaneko H, Akiho H, et al. Evidence-based clinical practice guidelines for irritable bowel syndrome. Gastroenterology. 2015;50(1): $11-30$.

9. Oka T, Okumi H, Nishida S, et al. Effects of Kampo on functional gastrointestinal disorders. Biopsychosoc Med. 2014;8(1):5.

10. de Caires S, Steenkamp V. Use of Yokukansan (TJ-54) in the treatment of neurological disorders: a review. Phytother Res. 2010;24(9): 1265-1270.

11. Mizukami K, Asada T, Kinoshita T, et al. A randomized cross-over study of a traditional Japanese medicine (kampo), yokukansan, in the treatment of the behavioural and psychological symptoms of dementia. Int J Neuropsychopharmacol. 2009;12(2):191-199.

12. Okahara K, Ishida Y, Hayashi Y, et al. Effects of Yokukansan on behavioral and psychological symptoms of dementia in regular treatment for Alzheimer's disease. Prog Neuropsychopharmacol Biol Psychiatry. 2010;34(3):532-536.

13. Nakamura Y, Tajima K, Kawagoe I, Kanai M, Mitsuhata H. [Efficacy of traditional herbal medicine, Yokukansan on patients with neuropathic pain]. Masui. 2009;58(10):1248-1255. Japanese.

14. Linehan MM, Tutek DA, Heard HL, Armstrong HE. Interpersonal outcome of cognitive behavioral treatment for chronically suicidal borderline patients. Am J Psychiatry. 1994;151(12):1771-1776.
15. Shinno H, Utani E, Okazaki S, et al. Successful treatment with Yi-Gan San for psychosis and sleep disturbance in a patient with dementia with Lewy bodies. Prog Neuropsychopharmacol Biol Psychiatry. 2007; 31(7):1543-1545.

16. Shimizu S, Tanaka T, Tohyama M, Miyata S. Yokukansan normalizes glucocorticoid receptor protein expression in oligodendrocytes of the corpus callosum by regulating microRNA-124a expression after stress exposure. Brain Res Bull. 2015;114:49-55.

17. Katahira H, Sunagawa M, Watanabe D, et al. Antistress effects of Kampo medicine "Yokukansan" via regulation of orexin secretion. Neuropsychiatr Dis Treat. 2017;13:863-872.

18. Yamaguchi T, Tsujimatsu A, Kumamoto H, et al. Anxiolytic effects of yokukansan, a traditional Japanese medicine, via serotonin 5-HT $1 \mathrm{~A}$ receptors on anxiety-related behaviors in rats experienced aversive stress. J Ethnopharmacol. 2012;143(2):533-539.

19. Shimizu S, Tanaka T, Takeda T, Tohyama M, Miyata S. The Kampo medicine yokukansan decreases microRNA 18 expression and recovers glucocorticoid receptors protein expression in the hypothalamus of stressed mice. Biomed Res Int. 2015;2015:797280.

20. Sempuku S. [Retrospective clinical study of Yokukansankachinpihange done at Sempuku clinic]. J Japan Assoc Oriental Psychosom Med. 2006;21(1/2):17-21. Japanese.

21. Qin J, Feng M, Wang C, Ye Y, Wang PS, Liu C. Oxytocin receptor expressed on the smooth muscle mediates the excitatory effect of oxytocin on gastric motility in rats. Neurogastroenterol Motil. 2009; 21(4):430-438.

22. Wang R, Guo LY, Suo MY, et al. Role of the nitrergic pathway in motor effects of oxytocin in rat proximal colon. Neurogastroenterol Motil. 2016;28(12):1815-1823.

23. Amico JA, Miedlar JA, Cai HM, Vollmer RR. Oxytocin knockout mice: a model for studying stress-related and ingestive behaviours. Prog Brain Res. 2008;170:53-64.

24. Zheng J, Babygirija R, Bülbül M, Cerjak D, Ludwig K, Takahashi T. Hypothalamic oxytocin mediates adaptation mechanism against chronic stress in rats. Am J Physiol. 2010;299(4):946-953.

25. Matsunaga M, Konagaya T, Nogimori T, et al. Inhibitory effect of oxytocin on accelerated colonic motility induced by water-avoidance stress in rats. Neurogastroenterol Motil. 2009;21(8):856-e59.

26. Babygirija R, Zheng J, Ludwig K, Takahashi T. Central oxytocin is involved in restoring impaired gastric motility following chronic repeated stress in mice. Am J Physiol Regul Integr Comp Physiol. 2010; 298(1):R157-R165.

27. Monstein HJ, Grahn N, Truedsson M, Ohlsson B. Oxytocin and oxytocin-receptor mRNA expression in the human gastrointestinal tract: a polymerase chain reaction study. Regul Pept. 2004;119(1-2):39-44.

28. Xie DP, Chen LB, Liu CY, Liu JZ, Liu KJ. Effect of oxytocin on contraction of rabbit proximal colon in vitro. World $J$ Gastroenterol. 2003;9(1):165-168.

29. Yang X, Xi TF, Li YX, et al. Oxytocin decreases colonic motility of cold water stressed rats via oxytocin receptors. World J Gastroenterol. 2014;20(31):10886-10894.

30. Duridanova DB, Nedelcheva MD, Gagov HS. Oxytocin-induced changes in single cell $\mathrm{K}^{+}$currents and smooth muscle contraction of guinea-pig gastric antrum. Eur J Endocrinol. 1997;136(5):531-538.

31. Uchida N, Egashira N, Iwasaki K, Fujiwara M. Yokukansan inhibits social isolation-induced aggression and methamphetamine-induced hyperlocomotion in rodents. Biol Pharm Bull. 2009;32(3):372-375.

32. Neumann ID, Wigger A, Torner L, Holsboer F, Landgraf R. Brain oxytocin inhibits basal and stress-induced activity of the hypothalamopituitary-adrenal axis in male and female rats: partial action within the paraventricular nucleus. J Neuroendocrinol. 2000;12(3):235-243.

33. Neumann ID. Involvement of the brain oxytocin system in stress: interactions with the hypothalamo-pituitary-adrenal axis. Prog Brain Res. 2002;139:147-162.

34. Saegusa Y, Takeda H, Muto S, et al. Decreased plasma ghrelin contributes to anorexia following novelty stress. Am J Physiol Endocrinol Metab. 2011;301(4):E685-E696. 
35. Matsunaga M, Konagaya $\mathrm{T}$, Nogimori $\mathrm{T}$, et al. Inhibitory effect of oxytocin on accelerated colonic motility induced by water-avoidance stress in rats. Neurogastroenterol Motil. 2009;21:856-e59.

36. Williams CL, Villar RG, Peterson JM, Burks TF. Stress-induced changes in intestinal transit in the rat: a model for irritable bowel syndrome. Gastroenterology. 1988;94(3):611-621.

37. Cetinel S, Hancioğlu S, Sener E, et al. Oxytocin treatment alleviates stress-aggravated colitis by a receptor-dependent mechanism. Regul Pept. 2009;160(1-3):146-152.

38. Miyashita T, Yamaguchi T, Motoyama K, Unno K, Nakano Y, Shimoi K. Social stress increases biopyrrins, oxidative metabolites of bilirubin, in mouse urine. Biochem Biophys Res Commun. 2006;349(2):775-780.

39. Kito Y, Teramoto N. Effects of Hange-shashin-to (TJ-14) and Keishika-shakuyaku-to (TJ-60) on contractile activity of circular smooth muscle of the rat distal colon. Am J Physiol Gastrointest Liver Physiol. 2012;303(9):1059-1066.

40. Egashira N, Iwasaki K, Ishibashi A, et al. Repeated administration of Yokukansan inhibits DOI-induced head-twitch response and decreases expression of 5-hydroxytryptamine (5-HT)2A receptors in the prefrontal cortex. Prog Neuropsychopharmacol Biol Psychiatry. 2008;32(6):1516-1520.

41. Takeda A, Itoh H, Tamano H, Yuzurihara M, Oku N. Suppressive effect of Yokukansan on excessive release of glutamate and aspartate in the hippocampus of zinc-deficient rats. Nutr Neurosci. 2008;11(1):41-46.

42. Kawakami Z, Ikarashi Y, Kase Y. Glycyrrhizin and its metabolite 18 beta-glycyrrhetinic acid in glycyrrhiza, a constituent herb of Yokukansan, ameliorate thiamine deficiency-induced dysfunction of glutamate transport in cultured rat cortical astrocytes. Eur J Pharmacol. 2010; 626(2-3):154-158.

43. Kawakami Z, Ikarashi Y, Kase Y. Isoliquiritigenin is a novel NMDA receptor antagonist in kampo medicine Yokukansan. Cell Mol Neurobiol. 2011;31(8):1203-1212.

44. Iványi T, Wiegant VM, de Wied D. Differential effects of emotional and physical stress on the central and peripheral secretion of neurohypophysial hormones in male rats. Life Sci. 1991;48(13):1309-1316.
45. Zelena D, Langnaese K, Domokos A, et al. Vasopressin administration into the paraventricular nucleus normalizes plasma oxytocin and corticosterone levels in Brattleboro rats. Endocrinology. 2009;150(6): 2791-2798.

46. Onaka T, Yagi K. Effects of novelty stress on vasopressin and oxytocin secretion by the pituitary in the rat. J Neuroendocrinol. 1993;5(4): 365-369.

47. Mizoguchi K, Tanaka Y, Tabira T. Anxiolytic effect of a herbal medicine, yokukansan, in aged rats: involvement of serotonergic and dopaminergic transmissions in the prefrontal cortex. J Ethnopharmacol. 2009;127(1):70-76.

48. Ermisch A, Barth T, Rühle HJ, Skopková J, Hrbas P, Landgraf R. On the blood-brain barrier to peptides: accumulation of labelled vasopressin, DesGlyNH2-vasopressin and oxytocin by brain regions. Endocrinol Exp. 1985;19(1):29-37.

49. McGonigle P. Peptide therapeutics for CNS indications. Biochem Pharmacol. 2012;83(5):559-566.

50. Zhang Y, Gray TS, D'Souza DN, et al. Desensitization of 5-HT $\mathrm{HA}_{1 \mathrm{~A}}$ receptors by $5-\mathrm{HT}_{2 \mathrm{~A}}$ receptors in neuroendocrine neurons in vivo. J Pharmacol Exp Ther. 2004;310(1):59-66.

51. Zhang Y, D'Souza D, Raap DK, et al. Characterization of the functional heterologous desensitization of hypothalamic 5-HT ${ }_{1 \mathrm{~A}}$ receptors after 5- $\mathrm{HT}_{2 \mathrm{~A}}$ receptor activation. J Neurosci. 2001;21(20):7919-7927.

52. Nishi A, Yamaguchi T, Sekiguchi K, et al. Geissoschizine methyl ether, an alkaloid in Uncaria hook, is a potent serotonin1A receptor agonist and candidate for amelioration of aggressiveness and sociality by yokukansan. Neuroscience. 2012;207:124-136.

53. Ueda T, Ugawa S, Ishida Y, Shimada S. Geissoschizine methyl ether has third-generation antipsychotic-like actions at the dopamine and serotonin receptors. Eur J Pharmacol. 2011;671(1-3):79-86.

54. Li J, Xue B, Han T, et al. Oxytocin down-regulates mesenteric afferent sensitivity via the enteric OTR/nNOS/NO/KATP pathway in rat. Neurogastroenterol Motil. 2015;27(1):51-62.
Neuropsychiatric Disease and Treatment

\section{Publish your work in this journal}

Neuropsychiatric Disease and Treatment is an international, peerreviewed journal of clinical therapeutics and pharmacology focusing on concise rapid reporting of clinical or pre-clinical studies on a range of neuropsychiatric and neurological disorders. This journal is indexed on PubMed Central, the 'PsycINFO' database and CAS,

\section{Dovepress}

and is the official journal of The International Neuropsychiatric Association (INA). The manuscript management system is completely online and includes a very quick and fair peer-review system, which is all easy to use. Visit http://www.dovepress.com/testimonials.php to read real quotes from published authors. 